\title{
Sodium silicate gel as a precursor for the in vitro nucleation and growth of a bone-like apatite coating in compact and porous polymeric structures
}

\author{
A.L. Oliveira ${ }^{\mathrm{a}, \mathrm{b}, *}$, P.B. Malafaya ${ }^{\mathrm{a}, \mathrm{b}}$, R.L. Reis ${ }^{\mathrm{a}, \mathrm{b}}$ \\ ${ }^{a}$ Department of Polymer Engineering, University of Minho, Campus de Azurém, 4800-058 Guimarães, Portugal \\ b3B's Research Group - Biomaterials, Biodegradables and Biomimetics, University of Minho, Campus de Gualtar, 4710-057 Braga, Portugal
}

Received 29 April 2002; accepted 22 January 2003

\begin{abstract}
In the present work, a new methodology to produce bioactive coatings on the surface of starch-based biodegradable polymers or other polymeric biomaterials is proposed. A sodium silicate gel is employed as an alternative nucleating agent to the more typical bioactive glasses for inducing the formation of a calcium-phosphate (Ca-P) layer. The method has the advantage of being able to coat efficiently both compact materials and porous 3D architectures aimed at being used on tissue replacement applications and as tissue engineering scaffolds. By means of this treatment, it is possible to observe the formation of an apatite-like layer, only after 6 hours of simulated body fluid immersion. For the porous materials, this layer could also be observed inside the pores, clearly covering the cell walls. Furthermore, an increase of the surface hydrophilicity (higher amount of polar groups in the surface) might contribute to the formation of silanol groups that also act as apatite inductors. After 30 days of SBF immersion, the apatite-like films exhibit a partially amorphous nature and the $\mathrm{Ca} / \mathrm{P}$ ratios became much closer to the value attributed to hydroxyapatite (1.67). The obtained results are very promising for the development of cancellous bone replacement materials and for pre-calcifying bone tissue engineering scaffolds.
\end{abstract}

(C) 2003 Elsevier Science Ltd. All rights reserved.

Keywords: Bioactive; Biodegradable polymers; Starch; Biomimetic coatings; Apatite nucleation; Sodium silicate

\section{Introduction}

It is important to recognize that there is no material suitable for a broad range of biomaterial applications. Nevertheless, biodegradable polymeric systems are becoming quite important in temporary applications for the repair and regeneration of healing tissues [1-3]. In this field, starch-based polymers are already wellknown biodegradable materials that may constitute a good alternative to the currently used bioresorbable biomaterials in applications such as bone replacement/ fixation $[3,4]$, novel hydrogels and partially degradable bone cements [5-7], carriers for the release of drugs/ bioactive agents [6-8] or temporary scaffolds for tissue

\footnotetext{
*Corresponding author. 3B's Research Group-Biomaterials, Biodegradables and Biomimetics, University of Minho, Campus de Gualtar, 4710-057 Braga, Portugal. Tel.: +351-253-604781; fax: $+351-253-604492$.

E-mail address: analeite@dep.uminho.pt (A.L. Oliveira).
}

engineering applications [8,9]. In fact, due to their processing versatility, they can exhibit a range of mechanical properties that can be analogous to the natural bone $[3,4]$ as well as a biocompatible behaviour already demonstrated by in vitro $[10,11]$ and in vivo studies [12].

On applications like bone replacement or fixation it can be advantageous for an orthopaedic implant to exhibit a bone bonding behaviour, i.e. to express bioactivity by creating an environment compatible with osteogenisis (bone growth), having a mineralizing interface developing as a natural bonding junction between living and non-living materials [13]. Therefore, an essential condition for a material to bond to living bone is the formation of a biologically active bone-like calcium-phosphate (Ca-P) layer on its surface, in the living body. On the basis of these observations, a biomimetic process for coating an apatite layer on organic polymers or other type of materials was first developed by Kokubo and co-workers [14,15], being the 
materials are immersed in a simulated body fluid (SBF) to promote the nucleation and growth of a Ca-P bonelike layer on its surface, using bioactive silica-based glass particles as nucleating agents. However, to do this on a degradable polymer is not a very easy task, as the surface of the substrate (and $\mathrm{pH}$ around it) is continuously changing. Nevertheless, these biomimetic coatings have already been successfully produced on the surface of starch-based biodegradable polymers [16,17].

When considering materials with complex shapes, such as porous $3 \mathrm{D}$ architectures, there is a considerable difficulty on forming an apatite coating, since the apatite nuclei will preferentially form on the surfaces which are facing the bioactive glass particles. To overcome this obstacle a new biomimetic methodology to produce bioactive coatings on the surface of starch based or other polymeric biomaterials is proposed in the present work, using a sodium silicate gel as alternative nucleating agent. Sodium silicate gel can reach inside the pores of porous 3D architectures to be used on tissue replacement and in tissue engineering scaffolding [18-20]. This new methodology is aimed at: (i) reducing the incubation periods, (ii) improving of the adhesion strength between the coating and substrate, (iii) being able to coat the inside of pores in porous 3D architectures to be used on tissue replacement and as tissue engineering scaffolds and (iv) producing $\mathrm{Ca}-\mathrm{P}$ layers with different (tailored) Ca-P ratios.

\section{Materials and methods}

\subsection{Preparation of the samples}

As a natural polymer, starch exhibits a great potential to be used in biomedical applications. The studied material is based on a blend of starch/ethylene vinyl alcohol (SEVA-C) supplied by Novamont, Italy. The blend contains around $50 \%$ starch by weight, while the copolymer discloses a composition of $60 / 40 \mathrm{~mol} / \mathrm{mol}$. Compact samples were produced by injection moulding on a Klockner Desma FM-20, using a nozzle temperature of $170^{\circ} \mathrm{C}$. A high molecular weight polyethylene (HMWPE, Hoechst, Germany), also produced by injection moulding with a nozzle temperature of $190^{\circ} \mathrm{C}$, was used as a control to assess the possibility of coating polymers that do not uptake water. All compact samples were standard ASTM tensile test bars with a cross-section of $2 \times 4 \mathrm{~mm}^{2}$.

SEVA-C based 3D-architectures were also prepared. SEVA-C powder was mixed with hydrogen peroxide $\left(\mathrm{H}_{2} \mathrm{O}_{2}, 30 \% \mathrm{v} / \mathrm{v}\right)$ that acted as a blowing agent. Adequate quantity of $\mathrm{H}_{2} \mathrm{O}_{2}$ was first optimized and fixed at $1: 1(\mathrm{wt} / \mathrm{wt}$, with respect to the total weight of the blend in the samples). A consistent slurry dispersion of the blend with $\mathrm{H}_{2} \mathrm{O}_{2}$ was then obtained. The mixture was then processed by a previously developed microwave baking methodology and samples with $25 \times 10 \times 5 \mathrm{~mm}$ were prepared. A well-established polymeric foam, polyurethane, was used as a model control. See details on its production in Ref. [8]. Further information on the properties of starch-based polymers and its potential for biomedical applications may be found elsewhere [3-12].

\subsection{Sodium silicate methodology}

To produce the bioactive coatings, a commercially available sodium silicate gel from SIGMA-ALDRICH $\left(\mathrm{Na}_{2} \mathrm{SiO}_{3} \mathrm{H}_{2} \mathrm{O}\right.$, containing $\sim 14 \% \mathrm{NaOH}$ and $\sim 27 \%$ $\mathrm{SiO}_{2}, \mathrm{pH} \approx 13$ ) was used. The viscosity of the gel is $6 \times 10^{-2} \mathrm{~Pa} \mathrm{~s}^{-1}$. Other authors have used solutions based on sodium silicate gels $[18,19]$. However, to design this methodology as simple as possible (and that means to look at it as a possible technology), the sodium silicate gel was herein used with concentration and $\mathrm{SiO}_{2} /$ $\mathrm{Na}_{2} \mathrm{O}$ molar ratio as received [20]. On the other hand, the relatively high viscosity of the gel allows for the impregnation of the materials other than uptaking, which would seriously affect the mechanical and degradation behaviour of the material. The materials were "impregnated" for $24 \mathrm{~h}$ with the gel in a controlled atmosphere $\left(23 \pm 1{ }^{\circ} \mathrm{C} ; 55 \% \mathrm{RH}\right)$. After this treatment, the solution with the samples was diluted with $50 \%$ vol. of distilled water and stirred for $5 \mathrm{~min}$. This procedure was aimed at diminishing the viscosity of the gel in order to produce a homogeneous and thin layer of vitrified sodium silicate in the surface of the materials. The samples were removed from the solution and then dried in controlled atmosphere $\left(23 \pm 1^{\circ} \mathrm{C} ; 55 \% \mathrm{RH}\right)$.

\subsection{Water-uptake ability}

Water-uptake studies are of great importance for a biodegradable material, because when implanted, it will inevitably be in the presence of the body fluids that will diffuse into the bulk of the polymer as degradation is taking place. For water-uptake measurements, all the samples were weighted before being immersed in distilled water (at room temperature) and then every $2 \mathrm{~h}$, during the first $12 \mathrm{~h}$ of immersion. After that period, the weights started to be registered each $24 \mathrm{~h}$, until the end of the experiment time ( 7 days). The samples were carefully removed from the water containing flasks and immediately weighted for the determination of the wet weight as a function of the immersion time. Wateruptake is given by

Water absorbed $=\left[\left(m_{\mathrm{f}}-m_{\mathrm{i}}\right) / m_{\mathrm{i}}\right] 100$,

where $m_{\mathrm{i}}$ is the initial weight of the sample, and $m_{\mathrm{f}}$ is the sample weight after a given time of immersion. 


\subsection{Contact angle measurements}

In previous works, SEVA-C has been demonstrated to be a quite hydrophilic substrate [17,21]. It is also known that the presence of $\mathrm{OH}$ groups on the surface seems to facilitate the connection with an apatite layer, when it is nucleated by a biomimetic treatment [17,21]. Alkali attack, namely with $\mathrm{KOH}$, has already proved to be very effective in increasing the number of $\mathrm{OH}$ groups at the surface [17]. Since the used sodium silicate gel contains $\sim 14 \%$ of $\mathrm{NaOH}$, an increase is expected in the hydrophilicity of the surface which will have an important role during apatite formation. Contact angle measurements were performed for compact SEVA-C samples that were submitted to the sodium silicate gel treatment for $24 \mathrm{~h}$, in order to detect any eventual modification in the surface of the material. After treatment, the samples were washed in distilled water and dried in a controlled atmosphere $\left(23 \pm 1{ }^{\circ} \mathrm{C} ; 55 \%\right.$ $\mathrm{RH})$. Contact angle measurements were obtained by the sessile drop method using a standard contact angle apparatus (Krüss, Hamburg, Germany). The measurements were performed with the aid of an image analysis system (G2/G40) installed in the apparatus. Duplicate measurements were recorded for each drop deposition. The average values were recorded after $5 \mathrm{~s}$ of the drop deposition (settling time). Ten average values were recorded for each condition and a final average value was calculated. All the measurements were made at room temperature and the probe liquids were water and methylene iodide. The results obtained from both

Table 1

Surface tension $\left(\gamma_{l}\right)$ of water and the methylene iodide and its polar $\left(\gamma_{l}^{\mathrm{p}}\right)$ and disperse $\left(\gamma_{l}^{\mathrm{d}}\right)$ components

\begin{tabular}{lllr}
\hline & $\gamma_{l}$ & $\gamma_{l}^{\mathrm{d}}$ & $\gamma_{l}^{\mathrm{p}}$ \\
\hline Water & 72.8 & 21.8 & 51.0 \\
Methylene iodide & 50.8 & 50.8 & 0.0 \\
\hline
\end{tabular}

liquids were used to calculate the surface tension $(\gamma)$ according to a method proposed by Owens and Wendt [22]. According to this method the surface tension of each phase can be resolved into a polar $\left(\gamma_{l}^{\mathrm{p}}\right)$ and dispersive $\left(\gamma_{l}^{\mathrm{d}}\right)$ parts, as presented in Table 1. Using these two test liquids the resulting values of the surface tension were calculated by this method which is particularly useful for determination of the surface energy of low-energy surfaces (polymers).

\subsection{Apatite formation}

To produce the apatite coatings the substrates were submitted to a procedure inspired in the so-called biomimetic treatment, previously described by Kokubo and co-workers [13-15] and adapted by Reis et al. $[16,17]$. The procedure is schematized in Fig. 1. This standard biomimetic methodology was used as a control-reference for comparative purposes. In this way, it was possible to evaluate the efficacy of the hereby newly proposed methodology. On the other hand, using $1 \mathrm{X}$ SBF in the first week, equally for all samples, the nucleation is expected to be induced in a more organized way and therefore to promote a good adhesion between the coating and the substrate. Further studies will be carried out in order to support this theory by quantifying the adhesion strength at the interface. For the standard biomimetic coatings production, the treated samples were:

(i) first soaked in a $\mathrm{SBF}$ with an ion concentration nearly equal to human blood plasma (Table 2) in order to form apatite nuclei,

(ii) and then, after 7 days, soaked in another solution with ion concentrations $1.5 \times \mathrm{SBF}$ for making apatite nuclei grow. Another group of samples was submitted to step (i) but, after 7 days, they were soaked in a solution with ion concentrations of $2 \times \mathrm{SBF}$.

In fact, it is believed that the concentration of SBF solution influences the nature of the apatite formed
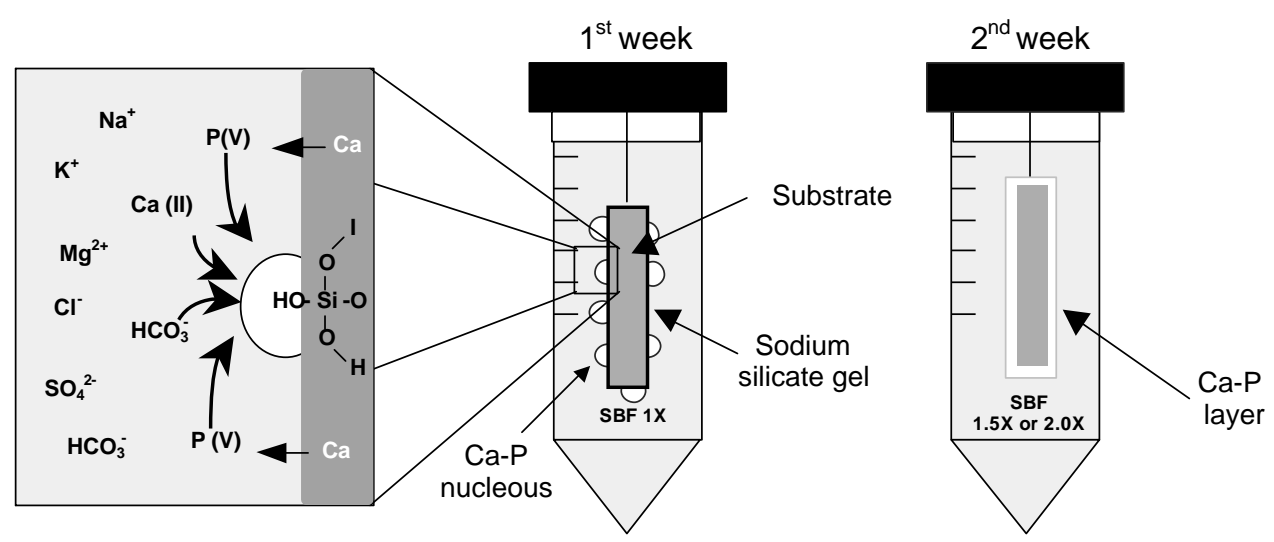

Fig. 1. Schematic drawing of the sodium silicate gel biomimetic methodology. Adapted by Reis et al. [16,17] from the procedure developed by Kokubo et al. [13-15]. 
Table 2

Ion concentrations and ionic activity products (IP) of human blood plasma and SBF solutions in the present study [23]

\begin{tabular}{|c|c|c|c|c|c|c|c|c|c|}
\hline \multirow[t]{2}{*}{ Solution } & \multicolumn{8}{|c|}{ Concentration/mM } & \multirow[t]{2}{*}{$\log$ IP } \\
\hline & $\mathrm{Na}^{+}$ & $\mathrm{K}^{+}$ & $\mathrm{Ca}^{2+}$ & $\mathrm{Mg}^{2+}$ & $\mathrm{Cl}^{-}$ & $\mathrm{HCO}_{3}^{-}$ & $\mathrm{HPO}_{4}^{2-}$ & $\mathrm{SO}_{4}^{2-}$ & \\
\hline Human plasma & 142.0 & 5.0 & 2.5 & 1.5 & 103.0 & 27.0 & 1.0 & 0.5 & -96.6 \\
\hline SBF $1.0 \times$ & 142.0 & 5.0 & 2.5 & 1.5 & 147.8 & 4.2 & 1.0 & 0.5 & -96.6 \\
\hline SBF $1.5 \times$ & 213.0 & 7.5 & 3.8 & 2.6 & 223.0 & 6.3 & 1.5 & 0.8 & -93.8 \\
\hline SBF $2.0 \times$ & 284.0 & 10.0 & 5.0 & 3.0 & 297.6 & 8.4 & 2.0 & 1.0 & -91.9 \\
\hline
\end{tabular}

during the growth stage [23]. Increasing the SBF concentration to 1.5 or $2 \times$, after the first week of apatite formation, will raise the ionic activity product from $10^{-96.6}$ to $10^{-91.9}$ respectively. In this way, it is expected to produce different (tailored) apatite coatings with different $\mathrm{Ca}-\mathrm{P}$ ratios and relative crystallinities. In both cases, study times were an incubation period up to 7 days (to understand the nucleation process) and a growing period up to 15 days.

\subsection{Scanning electron microscopy, energy dispersive spectroscopy and $X$-ray diffraction}

The morphological characterisation was carried out by Scanning electron microscopy (SEM) analysis, in a JEOL JSM $7301 \mathrm{~F}$. All the samples were coated with a thin film of carbon, by ion sputtering, prior to any observation. The electron beam energies were 10 and $12 \mathrm{KeV}$.

A half-quantitative characterisation, using well-established calibration sub-routines of the atomic concentrations of $\mathrm{Ca}$ and $\mathrm{P}$ without the coatings, was performed by energy dispersive spectroscopy (EDS), in a Rontec spectrometer. $\mathrm{Ca}, \mathrm{P}, \mathrm{Mg}, \mathrm{K}$ and $\mathrm{Na}$ amounts were quantified. From these results $\mathrm{Ca} / \mathrm{P}$ ratios were calculated. Considering the possibility of $\mathrm{Mg}^{2+}, \mathrm{Na}^{+}$and $\mathrm{K}^{+}$, present in the SBF, substituting the $\mathrm{Ca}^{2+}$ in the crystalline network of the apatite, the following relation was also calculated: $(\mathrm{Ca}+\mathrm{Na}+\mathrm{Mg}+\mathrm{K}) / \mathrm{P}$.

Thin-film X-ray Diffraction (TF-XRD, $1^{\circ}$ incidence angle) spectra were also acquired in a Rigaku equipment at $60 \mathrm{kV}$ at $30 \mathrm{~mA}$ in order to identify the crystalline phases present in the several Ca-P layers.

\section{Results and discussion}

\subsection{Water-uptake ability}

Fig. 2 shows the water-uptake versus time for SEVA$\mathrm{C}$ compact (Fig. 2a) and porous (Fig. 2b) structures, untreated and treated with sodium silicate. For compact structures, the equilibrium hydration degree of untreated samples is about $25 \%$, after $50 \mathrm{~h}$. This hydrophilic behaviour is mainly a result of the presence of starch and vinyl alcohol hydroxyl groups, as it has been
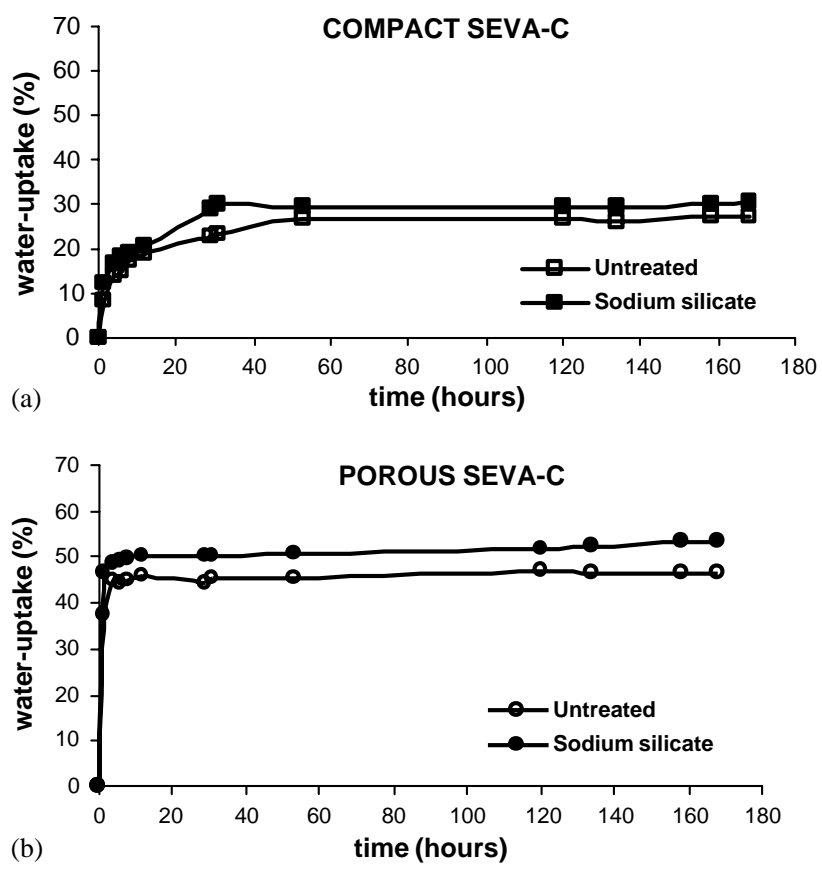

Fig. 2. Water-uptake (\%) versus time for untreated and sodium silicate treated (a) compact and (b) porous SEVA-C samples.

previously described [24]. Untreated porous structures achieve the equilibrium hydration degree, around $45 \%$, after the first $10 \mathrm{~h}$ of water uptaking. This higher hydrophilicity may result from the existence of high amounts of polar groups available in the structure after reaction of hydrogen peroxide with starch. On the other hand, porous structures have a higher specific surface than compact ones, which allows for a higher wateruptake. With sodium silicate treatment the amount of water uptake increases around $5 \%$ in both types of structures, this observation being more significant in the case of the compact material. The materials used as controls (compact HMWPE and porous PU) did not uptake water after the sodium silicate treatment.

\subsection{Contact angle measurements}

Understanding the surface behaviour of a biomaterial in contact with hydrated media is of great importance to predict interactions of a certain material with the surrounding tissues, when it is applied in a particular 
Table 3

Water $\left(\theta_{\mathrm{w}}\right)$ and methylene iodide $\left(\theta_{\mathrm{m}}\right)$ contact angle and surface energy measurements of SEVA-C untreated and after sodium silicate treatment for $24 \mathrm{~h}$

\begin{tabular}{|c|c|c|c|c|c|}
\hline & $\theta_{\mathrm{w}}\left({ }^{\circ}\right)$ & $\theta_{\mathrm{m}}\left({ }^{\circ}\right)$ & $\gamma_{\mathrm{s}}(\mathrm{mN} / \mathrm{m})$ & $\gamma_{\mathrm{s}}^{\mathrm{d}}(\mathrm{mN} / \mathrm{m})$ & $\gamma_{\mathrm{s}}^{\mathrm{p}}(\mathrm{mN} / \mathrm{m})$ \\
\hline Untreated SEVA-C & $63.4 \pm 1.85$ & $53.2 \pm 0.67$ & $45.9 \pm 1.09$ & $32.5 \pm 0.38$ & $13.4 \pm 1.08$ \\
\hline Treated SEVA-C & $29.7 \pm 3.79$ & $43.8 \pm 2.02$ & $68.0 \pm 2.02$ & $37.6 \pm 1.07$ & $30.3 \pm 1.83$ \\
\hline
\end{tabular}

biomedical application. Contact angle measurements were performed on compact SEVA-C samples. Table 3 presents the results concerning the average water/ methylene iodide contact angle $\left(\theta_{\mathrm{w}} / \theta_{\mathrm{m}}\right)$ and the average surface tension $\left(\gamma_{\mathrm{s}}\right)$ of the sodium silicate treated surfaces. This treatment, performed on the SEVA-C compact samples did modify the surface parameters. The average water contact angle had decreased from 63.4 to 29.7. An increment in the total surface energy, as a consequence of the increase of the polar contribution, was observed. Values changed from 45.9 to 68.0 after treatment. These significant changes can be attributed mainly to an increase in the polar contribution $\gamma_{\mathrm{s}}^{\mathrm{p}}$ (from 13.4 to 30.32 ) that resulted from an alkali attack by the sodium silicate gel, which can be compared to the previously studied $\mathrm{KOH}$ surface pre-treatment performed on SEVA-C substrates [17]. The increase of hydrophilicity after this treatment can be justified by the molecular hydroxyl-NaOH hydrogen bonding complexes, which are easily solvated by water molecules. The contact angle technique is not adequate to evaluate the hydrophilicity in case of porous SEVA-C samples. Nevertheless, the higher water-uptake ability (see Fig. 2) and existence of high amounts of polar groups available in the structure after reaction of hydrogen peroxide with starch can allow us to infer that porous SEVA-C surfaces are even more hydrophilic than compact ones.

\subsection{Apatite formation}

Figs. 3 and 4 show the SEM micrographs of the morphology of compact and porous SEVA-C before (Figs. 3a and b and Figs. 4a and b) and after immersion in SBF for $6 \mathrm{~h}$ and 30 days. In both cases it is possible to observe the formation of a very cohesive apatite-like layer only after $6 \mathrm{~h}$ of immersion in SBF (Figs. 3c and d and Figs. $4 \mathrm{c}$ and d) that became fragmented due to the swelling of the polymers. This indicates that the number of the nucleating sites on the surface of the substrates during the first hours of immersion is high, allowing for the formation of a dense and uniform apatite layer [20]. SEVA-C is a polar and quite a hydrophilic substrate, where the presence of $\mathrm{OH}$ groups in the surface tends to facilitate the connection with the apatite layer. It seems that a fairly strong bond could be formed between the polar groups and calcium ions of the apatite layer.
It has been shown by Li et al. [25] and Cho et al. [26] that heterogeneous nucleation of apatite can be induced from metastable solution, including physiologic solutions on those specific superficial sites, where there are $\mathrm{OH}$-containing groups. The proposed biomimetic methodology leads to an increase of the hydrophilicity (Table 3) and water-uptake ability (Fig. 2) of the polymers, resulting in the increase of polar groups in the surface. In this way, the polymers tend to absorb higher quantities of $\mathrm{Ca}^{2+}$ ions from the SBF solution. As a consequence, the $\mathrm{Ca}^{2+}$ ion concentration at the surface will be increased, leading to the formation of additional nucleating sites for the Ca-P coating formation. This phenomenon has already been reported for PEO/PBT copolymers [27], being related to a chelation effect. On the other hand, the formation at the surface of silanol groups $(\mathrm{Si}-\mathrm{OH})$ from sodium silicate gel will act as favourable sites for the apatite nucleation. As a result, a large number of apatite nuclei are rapidly formed on the surface. Subsequently, they grow spontaneously by consuming the calcium and phosphate ions from the surrounding fluids (the body fluid is already saturated with respect to the apatite).

Degradation of the starch-based polymers induces a greater degree of complexity to the reactions since it is continuously changing the composition of the solution adjacent to the interface, namely the $\mathrm{pH}$ and the polymer surface itself. This phenomenon has been previously described by Reis et al. [24]. The local conditions during reactions occurring at the polymer/ sodium silicate gel/solution interface may be very distinct in the bulk of the porous SEVA-C. Nevertheless, the apatite-like layer could also be observed inside the pores, clearly covering the cell walls. When comparing with the traditional biomimetic treatment, the latter is not so effective on reaching the bulk of porous structures [16]. Figs. $3 e$ and $f$ and Figs. $4 e$ and f, show the evolution of the apatites' morphology after 30 days of immersion in SBF (please remember that SBF concentration was raised to $1.5 \times$ after 7 days). This morphology is representative of the apatites that started to be formed after 7 days. Therefore, with increasing SBF concentration, it was possible to observe the formation of a new apatite layer, growing over the preformed cohesive Ca-P layer. In this stage the concentration of $\mathrm{Ca}$ and $\mathrm{P}$ in the solution is higher and the amount of nucleating sites at the surface seems to 

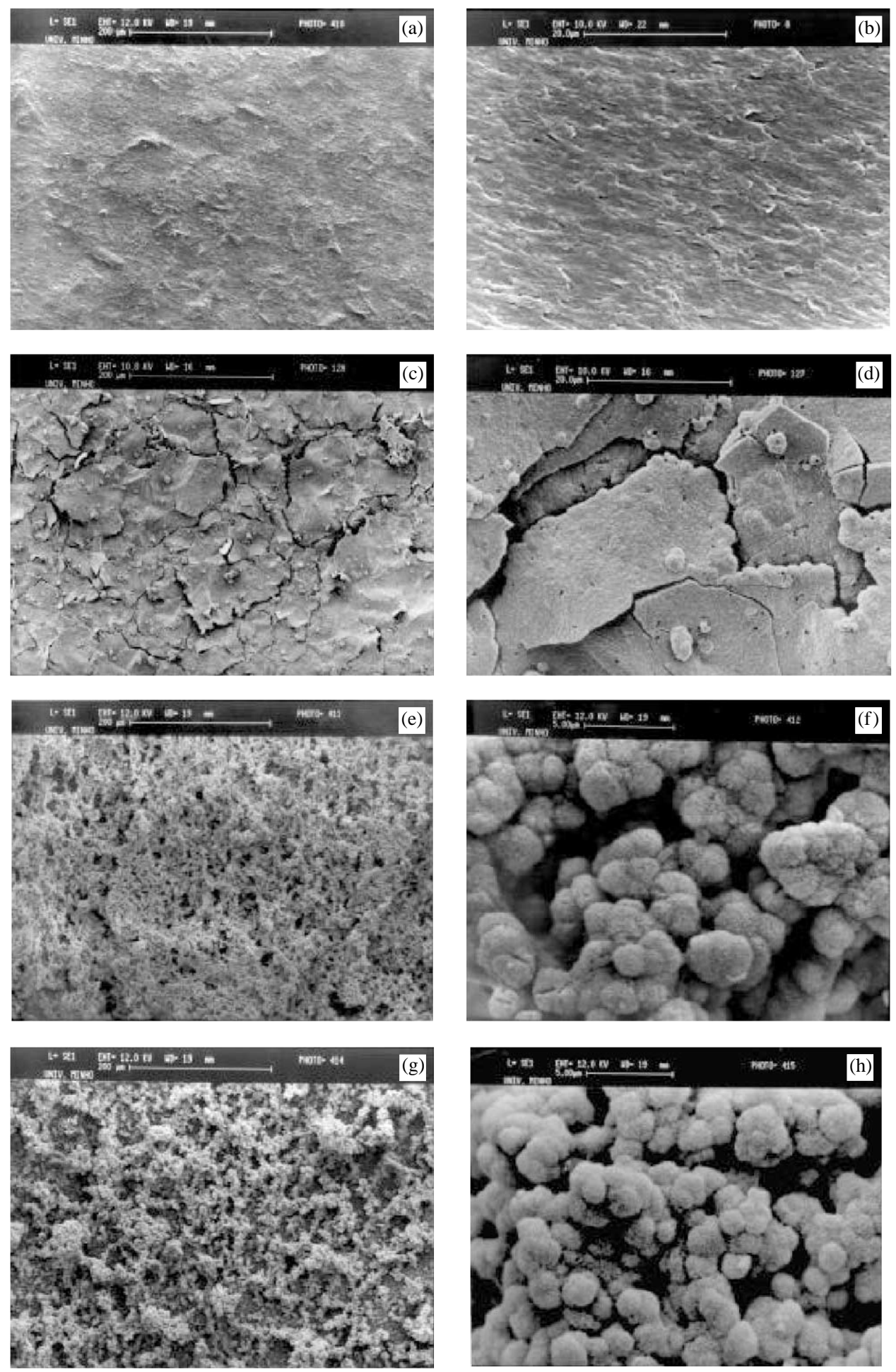

Fig. 3. SEM micrographs of compact SEVA-C treated with $(\mathrm{a}, \mathrm{b})$ sodium silicate and after (c, d) $6 \mathrm{~h},(\mathrm{e}, \mathrm{f}) 30$ days of immersion in $1.0 \times \mathrm{SBF}$ (raised to $1.5 \times \mathrm{SBF}$ after 7 days) and $(\mathrm{g}, \mathrm{h}) 30$ days of immersion in $1.0 \times \mathrm{SBF}$ (raised to $2.0 \times \mathrm{SBF}$ after 7 days).

have been decreased, leading to the formation of aggregates of nucleus that are growing into the so-called cauliflower morphology. This morphology was already reported for biomimetic coatings produced in this type of materials $[16,17]$. In case of compact materials the amount of aggregates formed over the initial layer lead to the formation of a new porous layer. Figs. $3 \mathrm{~g}$ and $\mathrm{h}$ and Figs. $4 \mathrm{~g}$ and $\mathrm{h}$ show apatite layers formed after 30 days of immersion in SBF (in this case raised to $2.0 \times$ after 7 days). For higher magnifications it is possible to 

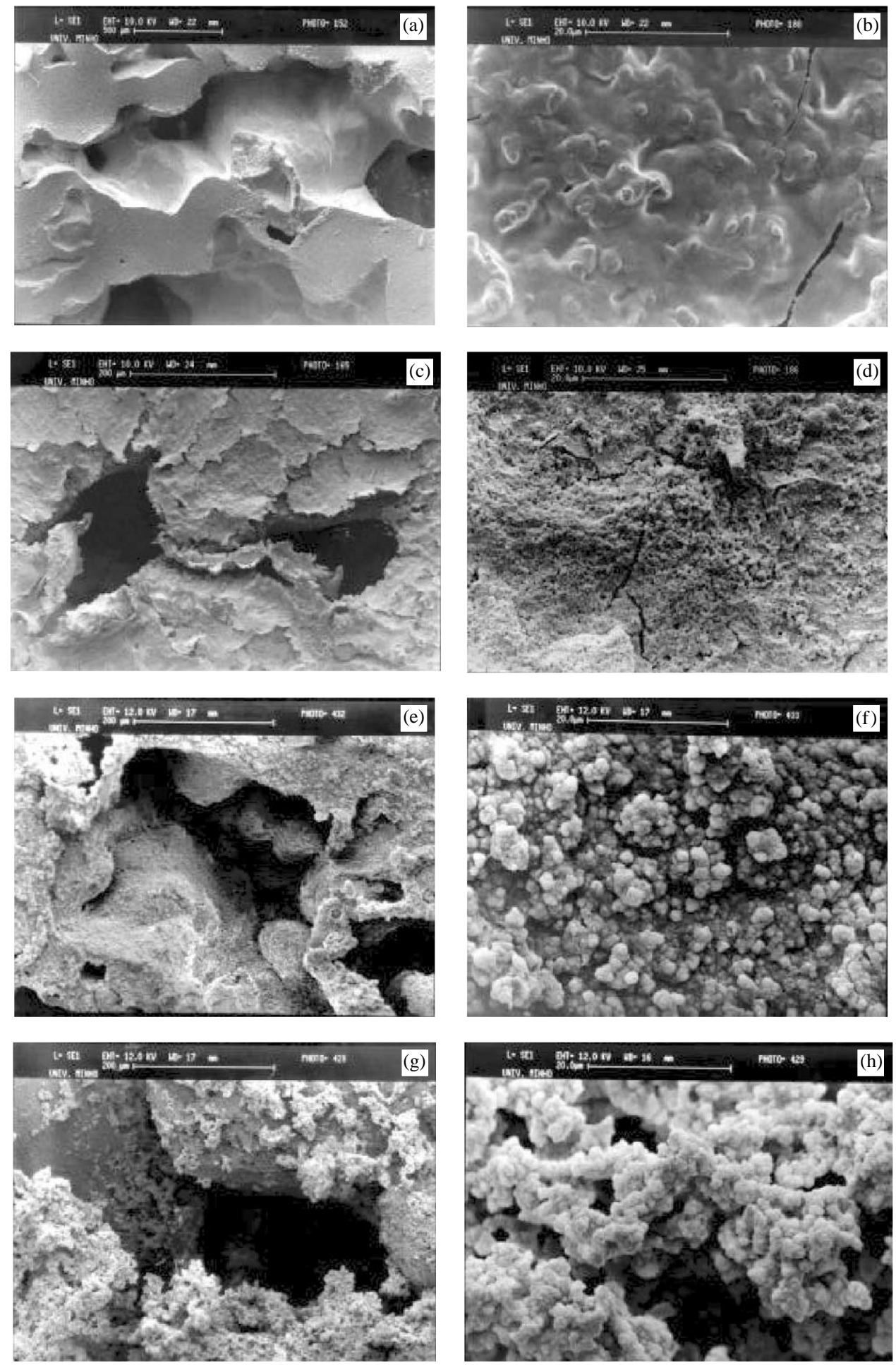

Fig. 4. SEM micrographs of porous SEVA-C treated with (a, b) sodium silicate and after (c, d) $6 \mathrm{~h},(\mathrm{e}, \mathrm{f}) 30$ days of immersion in $1 \times$ SBF (raised to $1.5 \times \mathrm{SBF}$ after 7 days) and $(\mathrm{g}, \mathrm{h}) 30$ days of immersion in $1 \times \mathrm{SBF}$ (raised to $2.0 \times \mathrm{SBF}$ after 7 days).

observe a needle-like structure, which is typical of this type of coatings. This morphology is particularly evident after immersing in SBF $2.0 \times$.

Tables 4 and 5 present the evolution of the $\mathrm{Ca} / \mathrm{P}$ and $(\mathrm{Ca}+\mathrm{Mg}+\mathrm{Na}+\mathrm{K}) / \mathrm{P}$ ratios of the apatites formed on compact and porous SEVA-C after immersion in SBF $(1.5 \times$ or $2.0 \times$ after 7 days $)$ for different periods up to 30 days. Apatites formed in a solution often replace the $\mathrm{Ca}^{2+}$ ion site with small amounts of $\mathrm{Na}^{+}, \mathrm{Mg}^{2+}$, or $\mathrm{K}^{+}$ ions. The presence of these ions in the crystalline 
network of the apatite was evaluated. In fact, for the first stages of immersion in SBF there is a considerable difference between $\mathrm{Ca} / \mathrm{P}$ and $(\mathrm{Ca}+\mathrm{Mg}+\mathrm{Na}+\mathrm{K}) / \mathrm{P}$, $\mathrm{Na}^{+}$and $\mathrm{Mg}^{+}$being the main contributors for the

Table 4

$\mathrm{Ca} / \mathrm{P}$ and $(\mathrm{Ca}+\mathrm{Mg}+\mathrm{Na}+\mathrm{K}) / \mathrm{P}$ ratios of the apatites formed on compact SEVA-C substrates, after immersion in SBF $1 \mathrm{X}$ and SBF $1.5 \times$ or $1.0 \times$ after 7 days

\begin{tabular}{cll}
\hline Time $(\mathrm{h})$ & $\mathrm{Ca} / \mathrm{P}$ & $(\mathrm{Ca}+\mathrm{Na}+\mathrm{Mg}+\mathrm{K}) / \mathrm{P}$ \\
\hline 6 & 1.34 & 2.58 \\
12 & 1.33 & 3.32 \\
24 & 1.44 & 1.76 \\
96 & 1.22 & 1.63 \\
192 & 1.57 & 1.85 \\
$720^{\mathrm{a}}$ & 1.62 & 1.92 \\
$720^{\mathrm{b}}$ & 1.54 & 1.72 \\
\hline
\end{tabular}

${ }^{\mathrm{a}} \mathrm{SBF} 1.5 \times$.

${ }^{\mathrm{b}} \mathrm{SBF} 2.0 \times$.

Table 5

$\mathrm{Ca} / \mathrm{P}$ and $(\mathrm{Ca}+\mathrm{Mg}+\mathrm{Na}+\mathrm{K}) / \mathrm{P}$ ratios of the apatites formed on porous SEVA-C substrates, after immersion in SBF $1 \times$ and SBF $1.5 \times$ or $2.0 \times$ after 7 days

\begin{tabular}{rll}
\hline Time $(\mathrm{h})$ & $\mathrm{Ca} / \mathrm{P}$ & $(\mathrm{Ca}+\mathrm{Na}+\mathrm{Mg}+\mathrm{K}) / \mathrm{P}$ \\
\hline 6 & 1.41 & 3.29 \\
12 & 1.39 & 1.77 \\
24 & 1.40 & 1.79 \\
96 & 1.52 & 1.70 \\
192 & 1.55 & 1.72 \\
$720^{\mathrm{a}}$ & 1.58 & 1.73 \\
$720^{\mathrm{b}}$ & 1.55 & 1.66 \\
\hline
\end{tabular}

${ }^{\mathrm{a}} \mathrm{SBF} 1.5 \times$.

${ }^{\mathrm{b}} \mathrm{SBF} 2.0 \times$. presented values. The presence of considerable amounts of $\mathrm{Na}^{+}$in the apatites formed in the first hours can be justified by the existence of these ions at the surface, resulting from adsorption during impregnation with sodium silicate gel. Considerable amounts of $\mathrm{Mg}^{2+}$ were also detected in the first hours. This phenomenon has already been reported for $\mathrm{KOH}$-treated SEVA-C substrates [17], and is presently under study, by preincubating SEVA-C in a supersaturated solution of $\mathrm{MgCl}_{2}$, in order to study the effect of $\mathrm{Mg}^{2+}$ in the nucleation and growth of an apatite layer. The $\mathrm{Ca} / \mathrm{P}$ ratios, both for compact and porous SEVA-C, tend to increase with immersion time in SBF, to values in the range between tricalcium phosphate (TCP, 1.5) and HA (1.67). When an apatite is formed from an aqueous solution, some sites for the $\mathrm{PO}_{4}^{3-}$ are partially substituted by $\mathrm{HPO}_{4}^{2-}$ and $\mathrm{CO}_{3}^{2-}$ ion substituting for the $\mathrm{PO}_{4}^{3-}$ when compared with the currently found one for bone apatite $(5.80 \mathrm{wt} \%)$ [23]. This result can be justified by a lower concentration of $\mathrm{HCO}_{3}^{-}$in the SBFs produced, when compared to human blood plasma (Table 2). After 30 days, it is possible to observe a decrease in the $\mathrm{Ca} / \mathrm{P}$ values of the apatites formed in the materials immersed in SBF $2.0 \times$ after 7 days, when compared with values resulting from a second immersion in SBF $1.5 \times$. This decrease with increase in the ionic activity product (IP) of the SBF solution that calculated $\mathrm{H}_{2} \mathrm{PO}_{4}^{-}, \mathrm{HPO}_{4}^{2-}$ and $\mathrm{PO}_{4}^{3-}$ concentration of SBF with different IPs was already reported by Kim et al. [23]. Since $\mathrm{H}_{2} \mathrm{PO}_{4}^{-}$ion concentration increases appreciably with increasing IP, compared with the other phosphate ions, so it is possible to assume that the degree of substitution of these ions for the $\mathrm{PO}_{4}^{3-}$ ions also increases appreciably with increasing IP, compared
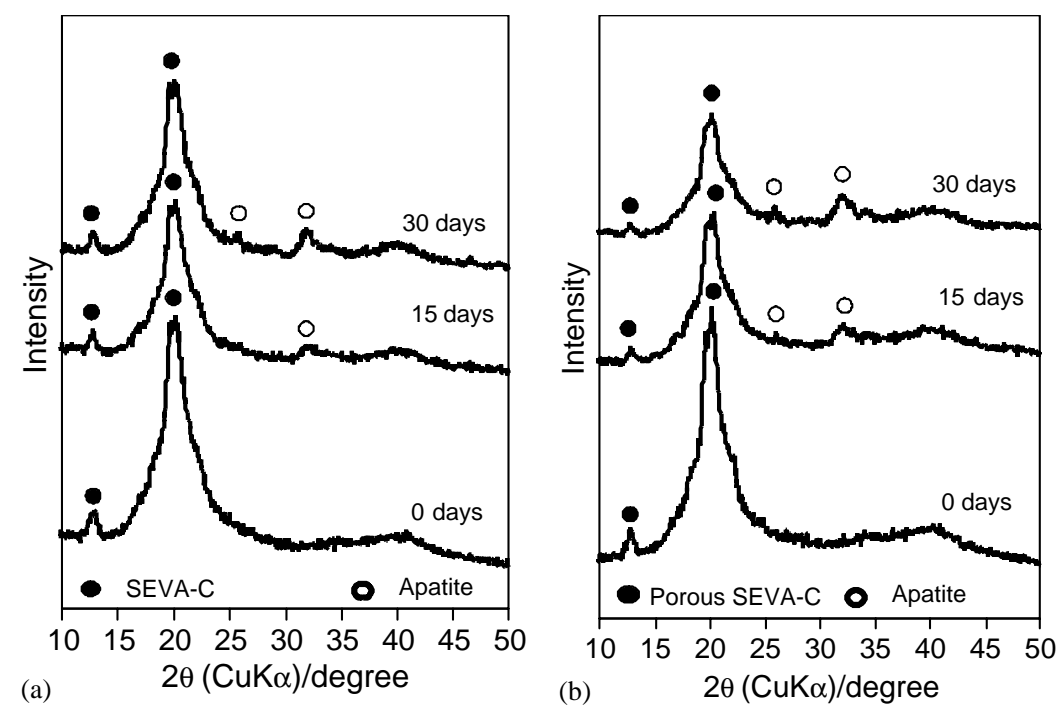

Fig. 5. Thin-film X-ray diffraction patterns of the films formed after treatment with sodium silicate. (a) Compact SEVA-C after 0,15 and 30 days of immersion in $1.0 \times \mathrm{SBF}$ (raised to $1.5 \times \mathrm{SBF}$ after 7 days). (b) Compact SEVA-C 0, 15 and 30 days of immersion in $1 \times \mathrm{SBF}$ (raised to $2.0 \times \mathrm{SBF}$ after 7 days). 
with the other phosphate ions, so it is possible to assume that the degree of substitution of these ions for the $\mathrm{PO}_{4}^{3-}$ ions also increases, leading to an increase in the $\mathrm{Ca}^{2+}$ deficiency [23]. This deficiency results from vacancies produced in the sites for the $\mathrm{Ca}^{2+}$ ions to maintain electrical neutrality. Figs. 5 and 6 present the TF-XRD patterns of the surface of compact and porous SEVA-C, before and after immersion in SBF, which were raised to (a) $1.5 \times$ or (b) $2.0 \times$ after the first week. These patterns suggest poor crystalline peaks mainly corresponding to hydroxylapatite, for the longer SBF immersion periods. Nevertheless, when increasing, the IP to $2 \times \mathrm{SBF}$, the crystallinity of the formed layers seems to be higher. It is well-known that bone apatite also presents a high amorphous content. The layers formed are consequently approaching bone apatite structure. In case of porous materials there is a more accentuated decrease in the intensity of the polymer peak with immersion time. This means that a thicker layer of apatite is growing. This is probably related with the high hydrophilicity exhibited by these materials (see Fig. 2), which will allow for the formation of more nucleation sites for the growth of an apatite layer.

In Fig. 7, it is possible to observe that no apatite layer was observed in the surface of treated PE (Fig. 7a) and PU foams (Fig. 7b), even after raising the SBF concentration to $2.0 \times$ after 7 days. On the treated PE compact substrates and PU foams, used as controls, this methodology was not effective in producing a Ca-P layer. This indicates that this methodology is much more adequate for materials that have a strong swelling ability. In fact, even with the well-known difficulties
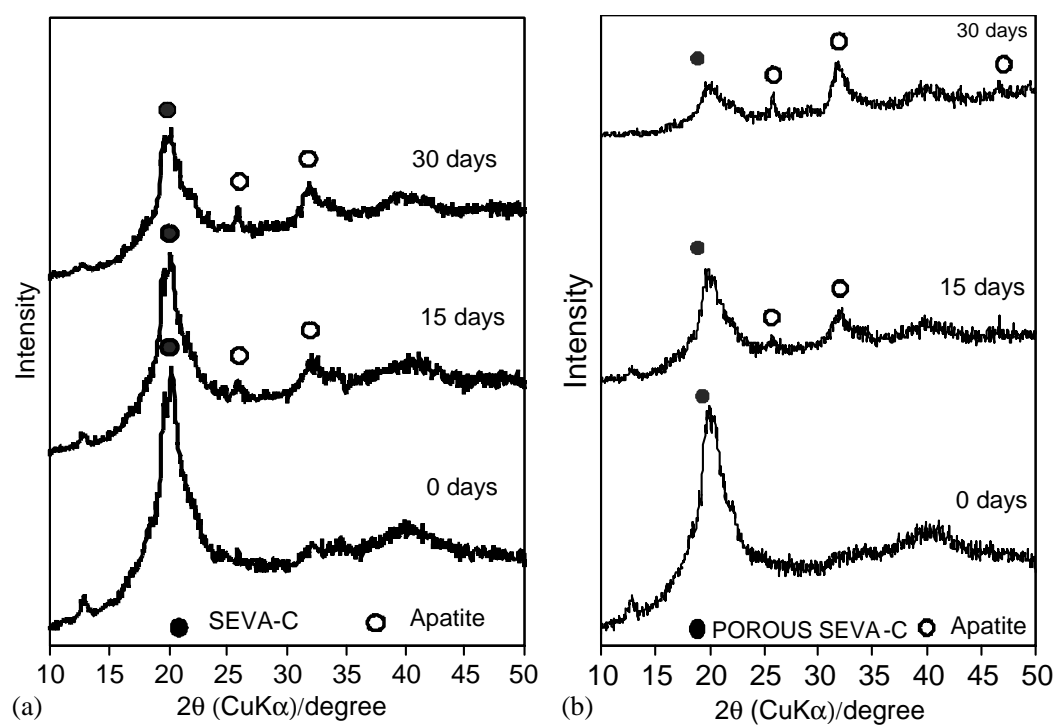

Fig. 6. Thin-film X-ray diffraction patterns of the films formed after treatment with sodium silicate. (a) Compact SEVA-C after 0,15 and 30 days of immersion in $1.0 \times \mathrm{SBF}$ (raised to $1.5 \times \mathrm{SBF}$ after 7 days). (b) Compact SEVA-C 0, 15 and 30 days of immersion in $1 \times \mathrm{SBF}$ (raised to $2.0 \times \mathrm{SBF}$ after 7 days).
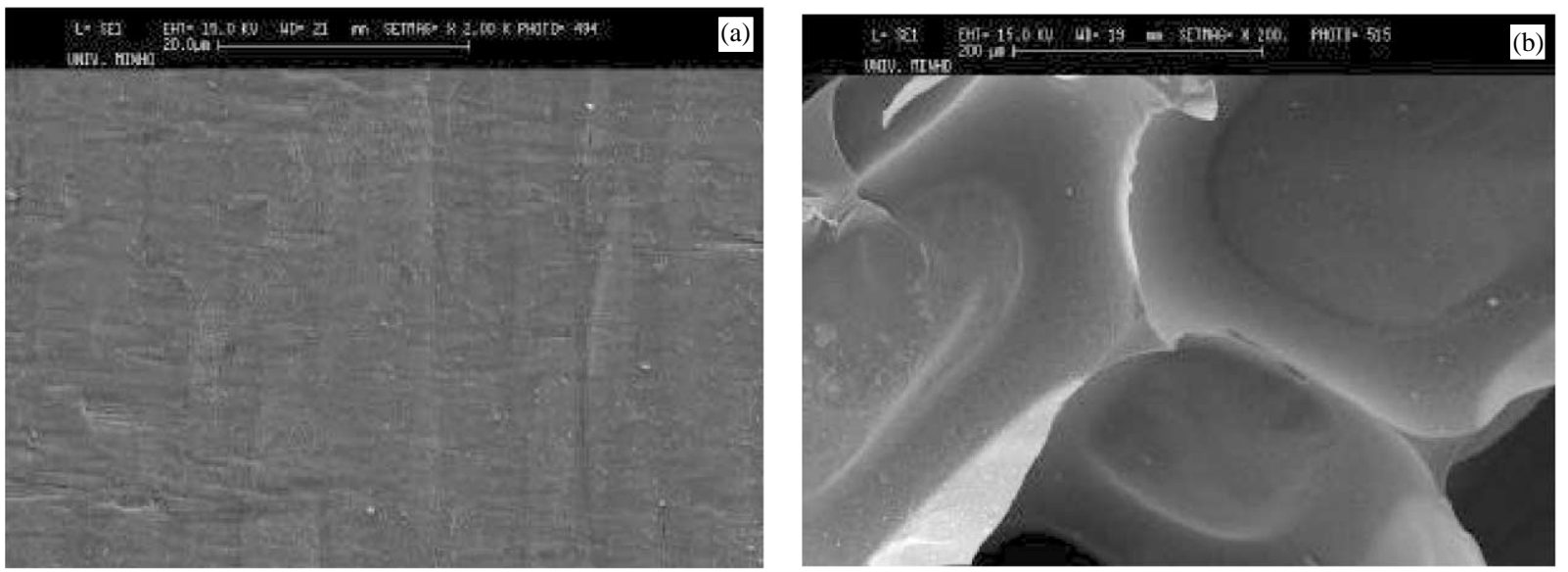

Fig. 7. SEM micrograph of (a) PE and (b) PU materials treated with sodium silicate and after 30 days of immersion in $1 \times \mathrm{SBF}($ raised to $2.0 \times \mathrm{SBF}$ after 7 days). 
associated to biodegradable polymers, rising from continuous $\mathrm{pH}$ and surface changes as a function of time, the methodology was successful in generating Ca-P coatings.

\section{Conclusions}

The sodium silicate treatment resulted in the faster formation of a clear apatite-like layer on the surface of compact and porous starch-based biodegradable polymers that could be observed only after $6 \mathrm{~h}$ of immersion in SBF. For the porous materials, this layer could also be observed inside the pores, clearly covering the cell walls. The $\mathrm{Ca} / \mathrm{P}$ ratios, both for compact and porous SEVA-C, tend to increase with immersion time in SBF, to values in the range between TCP and HA. TF-XRD patterns show the formation of a partially amorphous Ca-P layer, with the crystalline peaks mainly corresponding to hydroxylapatite (for the longer SBF immersion periods). The layers formed are consequently approaching bone apatite structure. The results obtained are very promising for the development of cancellous bone replacement materials and for precalcifying bone tissue engineering scaffolds. The proposed methodology is adequate, efficient and easy to be applied for the coating of biodegradable polymers, in spite of the difficulties arising from continuous $\mathrm{pH}$ and surface changes as a function of time.

\section{References}

[1] Kohn J, Langer R. In: Ratner BD, Hoffman AS, Schoen FJ, Lemons JE, editors. Biomaterials science: an introduction to materials in medicine. London: Academic Press, 1996. p. 64.

[2] Thomson RC, Wake MC, Yaszemski M, Mikos AG. Biodegradable polymer scaffolds to regenerate organs. Adv Polym Sci 1995; 122:247-74.

[3] Reis RL, Cunha AM. Characterization of two biodegradable polymers of potential application within the biomaterials field. J Mater Sci: Mater Med 1995;6:786-92.

[4] Reis RL, Cunha AM, Allan PS, Bevis MJ. Mechanical behaviour of injection-moulded starch based polymers. Polym Adv Technol 1996;7:784-90.

[5] Espigares I, Elvira C, Mano J, Vasquez B, San Roman J, Reis RL. New biodegradable and bioactive acrylic bone cements based on starch blends and ceramic fillers. Biomaterials 2002;231:883-95.

[6] Pereira CS, Cunha AM, Reis RL, Vázquez B, San Roman J. New starch-based thermoplastic hydrogels for use as bone cements or drug-delivery carriers. J Mater Sci: Mater Med 1998;9 :825-33.

[7] Elvira C, Mano JF, San Román J, Reis RL. Starch based biodegradable hydrogels with potential biomedical applications as drug delivery systems. Biomaterials 2002;23:1955-66.

[8] Malafaya PB, Elvira C, Gallardo A, San Román J, Reis RL. Porous starch-based drug delivery systems processed by a microwave route. J Biomed Sci-Polym Ed 2001;12:1227-41.
[9] Gomes ME, Ribeiro AS, Malafaya PB, Reis RL, Cunha AM. A new approach based on injection moulding to produce biodegradable starch-based polymeric scaffolds: morphology, mechanical and degradation behaviour. Biomaterials 2001;22:883-9.

[10] Gomes ME, Reis RL, Cunha AM, Blitterswijk CA, De Bruijn J. Cytocompatibility and response of osteoblastic-like cells to starch-based polymers: effect of several additives and processing conditions. Biomaterials 2001;22:1911-7.

[11] Marques AP, Reis RL, Hunt JA. The biocompatibility of novel starch-based polymers and composites: in vitro studies. Biomaterials 2002;23:1471-8.

[12] Mendes SC, Reis RL, Bovell YP, Cunha AM, Van Blitterswijk C, De Bruijn J. Biocompatibility testing of novel starch based materials with potential application in orthopaedic surgery: a preliminary study. Biomaterials 2001;22:2057-64.

[13] Cao W, Hench LL. Bioactive materials. Ceram Int 1996;22: 493-507.

[14] Abe Y, Kokubo T, Yamamuro T. Apatite coating on ceramics, metals and polymers utilizing a biological process. J Mater Sci: Mater Med 1990;1:233-8.

[15] Tanashi M, Yao T, Kokubo T, Minoda M, Miyamoto T, Nakamura T, Yamamuro T. Apatite coating on organic polymers by biomimetic process. J Am Ceram Soc 1994;7:2805-8.

[16] Reis RL, Cunha AM, Fernandes MH, Correia RN. Treatments to induce the nucleation and growth of apatite-like layers on polymeric surfaces and foams. J Mater Sci: Mater Med 1997;8:897-905.

[17] Oliveira AL, Elvira C, Vasquez B, San Román J, Reis RL. Surface modification tailors the characteristics of biomimetic coatings nucleated on starch based polymers. J Mater Sci: Mater Med 1999;10:827-35.

[18] Miyaji F, Handa S, Kokubo T, Nakamura T. Apatite formation on polymers by biomimetic process using sodium silicate solution. In: Sedel L, Rey C, editors. Bioceramics, vol. 10. Amsterdam: Elsevier Science, 1997.

[19] Miyaji F, Kim H, Handa S, Kokubo T, Nakamura T. Bonelike apatite coating on organic polymers: novel nucleation process using sodium silicate solution. Biomaterials 1999;20:913-9.

[20] Oliveira AL, Malafaya PB, Reis RL. Sodium silicate gel induced self-mineralization of different compact and porous polymeric structures. In: Giannini S, Moroni A, editors. Bioceramics, vol. 13. Zurich: Trans Tech Publications, 2000. p. 5-78.

[21] Demirgöz D, Elvira C, Mano JF, Cunha AM, Piskin E, Reis RL. Chemical modification of starch based biodegradable polymeric blends: effects on water, degradation behaviour and mechanical properties. Polym Degrad Stabil 2000;70:161-70.

[22] Owens DK, Wendt RC. Estimation of Surface Free Energy of Polymers. J Appl Polym Sci 1969;13:1741-7.

[23] Kim H-M, Kishimto K, Miyaji F, Kokubo T, Yao T, Suetsugu Y, Tanaka J, Nakamura T. Composition and structure of the apatite formed on PET substrates in SBF modified with various ionic activity products. J Biomed Mater Res 1999;46:228-35.

[24] Reis RL, Mendes SC, Cunha AM, Bevis MJ. Processing and invitro degradation of starch/EVOH thermoplastic blends. Polym Int 1997;43:347-53.

[25] Li P, Ohtsuki C, Kokubo T, et al. Apatite coating on organic polymers by a biomimetic process. J Am Ceram Soc 1992;75: 2094-7.

[26] Cho S, Miyaji F, Kokubo T, Nakanishi K, Soga N, Nakamura T. Apatite-forming ability of silicate ion dissolved from sílica gels. J Biomed Mater Res 1996;32:375-81.

[27] Bakker D, Grote JJ, Vrouenraets CMF, Heseling SC, De Wijn JR, Van Blitterswijk CA. In: Heimke G, Soltesz U, Lee AJC, editors. Clinical implant materials. Amsterdam: Elsevier, 1990. p. $99-104$. 